\title{
Movement disorders in catatonia
}

\author{
Subhashie Wijemanne, Joseph Jankovic
}

- Additional material,

including videos, is published online only. To view please visit the journal online (http:// dx.doi.org/10.1136/jnnp-2014309098).

Department of Neurology, Parkinson's Disease Center and Movement Disorders Clinic, Baylor College of Medicine, Houston, Texas, USA

\section{Correspondence to} Dr Joseph Jankovic, Department of Neurology, Parkinson's Disease Center and Movement Disorders Clinic, Baylor College of Medicine, 6550 Fannin, Suite 1801, Houston, TX 77030, USA; josephj@bcm.edu

Received 31 July 2014 Revised 8 October 2014 Accepted 28 October 2014 Published Online First 19 November 2014

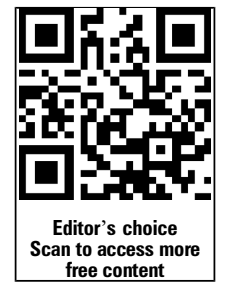

CrossMark

To cite: Wijemanne $S$, Jankovic J. J Neurol Neurosurg Psychiatry 2015;86:825-832.

\section{ABSTRACT}

Catatonia is a complex neuropsychiatric syndrome characterised by a broad range of motor, speech and behavioural abnormalities. 'Waxy flexibility', 'posturing' and 'catalepsy' are among the well-recognised motor abnormalities seen in catatonia. However, there are many other motor abnormalities associated with catatonia. Recognition of the full spectrum of the phenomenology is critical for an accurate diagnosis. Although controlled trials are lacking benzodiazepines are considered first-line therapy and N-Methyl-Daspartate receptor antagonists also appears to be effective. Electroconvulsive therapy is used in those patients who are resistant to medical therapy. An underlying cause of the catatonia should be identified and treated to ensure early and complete resolution of symptoms.

\section{INTRODUCTION}

Catatonia is a complex neuropsychiatric syndrome characterised by a broad range of motor, speech and behavioural abnormalities. 'Waxy flexibility', 'posturing' and 'catalepsy' are among the well-recognised motor abnormalities associated with catatonia. However, there is a wide spectrum of speech and other neurological abnormalities seen in this condition. This article attempts to summaries the clinical features of catatonia; discuss some diagnostic challenges, possible mechanisms and available treatment options in this poorly understood condition.

Catatonia was first described by German psychopathologist Karl Kahlbaum in Die Katatonie oder das Spannungsirresein in 1874 as a motor syndrome in patients with behavioural disorders. ${ }^{1} 2$ He considered catatonia as a distinct clinical entity with progressive symptoms. Catatonia was subsequently classified by psychopathologists Kraepelin and Bleuler as 'dementia praecox' (premature dementia), a condition which was later classified as schizophrenia. ${ }^{3}$ The uncertainty about its definition was partly responsible for the long-standing neglect of catatonia in clinical and scientific literature and for its frequent underdiagnosis. ${ }^{4}$ It is clear that catatonia is no longer limited to schizophrenia, and that it can be seen in the setting of a variety of other conditions such as psychiatric disorders other than schizophrenia, medical, neurological and surgical conditions, as well as in the setting of certain drugs and toxins. 567

The frequency of catatonia in acute psychiatric admissions is approximately $10 \%$, but estimates range from $5 \%$ to $20 \%$ based on diagnostic criteria used in prospective studies conducted during 1-12 months of observation at psychiatric units. ${ }^{4} \quad 8 \quad 9$ Other surveys have reported a prevalence ranging between $7.6 \%$ and $38 \%$ among all psychiatric patients. ${ }^{10}$ The percentage of catatonia due to a general medical condition is reported to range from $20 \%$ to $39 \% .^{11}$ Catatonia may be subtle and overlooked, which may account for reports suggesting a declining incidence. People with bipolar disorders probably constitute the largest subgroup of catatonic patients. ${ }^{5} 1012$ In a minority of cases, no cause is found and the current prevalence of idiopathic catatonia is unknown.

Owing to the wide range of underlying diagnoses, patients with catatonia may present as a medical or psychiatric emergency ${ }^{13}$ or develop symptoms during hospitalisation, such as in the intensive care unit (ICU), which can be challenging from a diagnostic standpoint. ${ }^{13}{ }^{14}$ Catatonia usually presents acutely but may present insidiously, and can be transient or chronic, and last for weeks, months and even years. ${ }^{15}$ Catatonic patients are at risk for severe complications such as pneumonia, decubitus ulcers, malnutrition, dehydration, contractures and thrombosis and delays in diagnosis and management are associated with increased morbidity. ${ }^{13}$ Although it may become life-threatening, ${ }^{16}$ catatonia has an excellent prognosis if recognised and treated early.

\section{DIAGNOSTIC CRITERIA AND RATING SCALES}

The diagnosis of catatonia is based on clinical observations. The revised diagnostic criteria were published in the fifth Diagnostic and Statistical Manual of Mental Disorders (DSM-V) in 2013. ${ }^{17}$ While the DSM-IV used different sets of criteria for diagnosis of catatonia in schizophrenia and primary mood disorders versus neurological/medical conditions, the revised DSM-V criteria can be applied across all of the different clinical settings. According to DSM-V criteria, to make a diagnosis of catatonia one has to have a minimum of 3 of the following 12 clinical features, either observed or elicited during examination: (1) mutism, (2) stupor, (3) catalepsy, (4) waxy flexiblity, (5) agitation, (6) negativism, (7) posturing, (8) mannerisms, (9) stereotypies, (10) grimacing, (11) echolalia, or (12) echopraxia. ${ }^{17}$ The criteria seem rather arbitrary, and the list of associated features highlights the clinical heterogeneity of this neuropsychiatric disorder.

Several rating scales have been developed for the assessment of catatonia. ${ }^{18}$ The Bush-Francis Catatonia Rating Scale (BFCRS) is the most widely used scale. This includes 23 items and up to 30 signs. Some of the signs (described below) are not listed in the DSM-V criteria, such as excitement, staring, rigidity, withdrawal, automatic obedience, impulsivity, ambitendency, grasp reflex, verbigeration, mitgehen, autonomic abnormality, combativeness and perseveration. 
There is also a screening version of BFCRS known as Bush-Francis Catatonia Rating Screening Instrument (BFCSI), which contains 14 most common catatonic signs (excitement, immobility/stupor, mutism, staring gaze, posturing/catalepsy, grimacing, echopraxia/echolalia, stereotypes, mannerisms, verbigeration, rigidity, negativism, waxy flexibility and withdrawal). If two or more of the BFCSI signs are present for $24 \mathrm{~h}$ or longer, catatonia should be considered as a possible diagnosis. To avoid overdiagnosis, signs such as 'impulsiveness' and 'combativeness' were excluded from the screening instrument. ${ }^{19}$ Items from the BFCRS are scored on a 0-3 point scale, whereas items from the BFCSI are scored as 'absent' or 'present'. Another catatonia rating scale, the Modified Rogers Scale (MRS), has also been validated.

The primary aim of this review is to draw attention to the broad spectrum of phenomenology associated with catatonia by highlighting the most characteristic clinical features and provide illustrative videos.

\section{CLINICAL FEATURES}

The catatonic syndrome is seen in two principal forms: hypokinetic (withdrawn type) or hyperkinetic (excited type). ${ }^{10}$ Some patients, however, may display features of both types during the course of the illness. Patients with hypokinetic or withdrawn type of catatonia, typically appear awake and watchful, but with minimal spontaneous speech and movement. It is commonly associated with mutism, stupor, negativism, obsessional slowness and posturing. Hyperkinetic or excited type catatonia is characterised by agitation, combativeness, disorganised overproductive speech (verbigeration), stereotypies, grimacing and echophenomena. There is no difference in the expression of catatonic symptoms based on the underlying cause, whether it is psychiatric or medical.

Mutism, manifested by minimal or no verbal communication, is probably the most frequently observed sign of catatonia in the acute hospital setting, but the diagnosis is not applicable if there is evidence of aphasia. ${ }^{2021}$ Although typically associated with hypokinetic catatonia, mutism can also accompany a hyperkinetic movement disorder. Catatonic stupor is manifested by patient's absence of movement or other reaction to any stimulus while awake. Patient is typically extremely hypoactive, immobile and minimally responsive to stimuli including pain. Stupor can occur independently or in combination with mutism. Differentiating sedation from catatonic stupor can be challenging, but the latter is usually associated with normal awake EEG. ${ }^{21}$ Patients with catatonia can go through periods of agitation during which they can injure themselves or others. These periods of agitation may be associated with autonomic instability manifested by hyperthermia, tachycardia and hypertension. Individuals in this excited state may display extreme hyperactivity with constant motor unrest and purposeless motor activity, and may eventually collapse from exhaustion.

One of the most recognisable clinical features of catatonia is posturing which refers to spontaneous and active maintenance of a posture against gravity (see online supplementary videos 1-3). Waxy flexibility refers the characteristic motor sign of catatonia elicited by the examiner who manipulates the body or extremities to assume certain postures which the patient can maintain for a prolong periods of time (see online supplementary videos 1-3). There may be an initial resistance which is soon followed by slow release, as if bending a warm candle hence the term waxy flexibility. ${ }^{15}$ Catalepsy refers to the maintenance of fixed postures in the sitting or standing position for prolong periods of time with minimal movement regardless of external stimuli, including pain (see online supplementary videos 1-3). The positions assumed by the patient may be unusual and appear uncomfortable to the observer. The patients can adopt statuesque postures with minimal movement lasting for several hours without any apparent fatigue or discomfort. Other examples include twisting of the body, standing on one leg like a stork, holding one arm outstretched for a long time, and squatting with extension of arms. Another dramatic posturing is the 'psychological pillow' where the patient lies in bed with the head and shoulder raised as if there is an imaginary pillow. The head is raised a few inches above the bed surface which is maintained for prolonged period of time.

In negativism there is increasing resistance to passive manipulation of the limbs which is known as gegenhalten or paratonia. When eliciting the phenomenon of gegenhalten, it appears to the examiner as if the patient is deliberately opposing the passive movement. ${ }^{22}$ Social negativism may include turning away when addressed, refusing to open the eyes and closing the mouth when offered food or liquids.

Stereotypy is a common movement disorder seen in catatonia (see online supplementary videos 1 and 3) which is defined as involuntary, coordinated, patterned, rhythmic, seemingly purposeless movement or utterance performed repeatedly over time. Some of the motor stereotypies that are seen in catatonia include body rocking, shoulder shrugging, hand waving, opening eye wide and then squeezing them shut, nose wrinkling, and repetitive mouth and jaw movements. Stereotypies may be accompanied by self-injurious behaviour, such as head banging, self-hitting, punching, biting, kicking and scratching directed at any body surface. In addition to motor stereotypies patients with catatonia can have phonic stereotypies which include repetitive, apparently meaningless utterances, such as sniffing, clicking, snorting, moaning and other meaningless sounds, similar to phonic tics (see online supplementary video 3 ). These patients can also have facial grimacing and exaggerated facial expressions (see online supplementary videos 1-3).

Mannerisms is another observed clinical feature which is characterised by repetitive, idiosyncratic movements or gestures that are unique to the individual such as using hands when talking. Echophenomena include echopraxia and echolalia. Echopraxia refers to mimicry of examiner's movements or imitation of other person's movements or gestures. Echolalia means nearly simultaneous repetition of words or phrases spoken by others.

Catatonic excitement refers to extreme hyperactivity with constant motor restlessness which is apparently non-purposeful. Although similar, catatonic excitement is different from akathisia in that it does not appear to be associated with a feeling of restlessness and an uncomfortable sensation or an urge to move. Patients with catatonia can have staring gaze where the eyes are focused at a distance with little eye contact (see online supplementary video 1 ). There is little or no visual scanning of environment and there is decreased blinking.

Rigidity consists of a stiff position which the patient attempts to maintain despite efforts to be moved. Catatonic rigidity is not typically accompanied by cogwheeling or tremor, which helps to differentiate from parkinsonian rigidity. The state of withdrawal, also interpreted as 'social negativism', is a condition manifested by the patient's refusal to eat, drink or make eye contact.

Some patients with catatonia can also demonstrate exaggerated cooperation for example, automatically obeying every instruction of the examiner which is known as automatic obedience (see online supplementary video 2). Automatic obedience can also mean the performance of tasks at the command of the examiner even though the tasks are inappropriate or dangerous such as by 
reaching into pocket and state: 'stick out your tongue, I want to prick it with a pin'. ${ }^{19}$ Mitmachen and Mitgehen are two forms of automatic obedience. In Mitmachen the body of the patient can be put into any posture, even if the patient is given instructions to resist. Mitgehen is an extreme form of automatic obedience in which the examiner is able to move the patient's body with the slightest touch, but unlike waxy flexibility the body part immediately returns to the original position. This can be tested by asking the patient to extend their arm and then place the examiners finger beneath the hand and try to raise the arm slowly using gentle push upwards after stating: 'Do NOT let me raise your arm'. When the examiner's finger retracts the patient's hand moves downward in an attempt to keep in physical contact with the examiner's finger. ${ }^{19}$ Catatonic patients can exhibit a great deal of impulsivity manifested by suddenly engaging in an inappropriate behaviour such as running down hallway, screaming or taking off clothes without any provocation. Ambitendency refers to a state of indecisive or hesitant movement (see online supplementary video 2). This could manifest as alternating cooperation and then resistance in following examiner's instructions. One can also elicit the grasp reflex, in which, the patient forcibly and repeatedly grasps the examiner's hand when offered. ${ }^{22}$ Verbigeration is the frequent repetition of meaningless words and phrases (see online supplementary video 3). Motor perseveration is manifested, for example, by persistence of a particular movement long after the original command or intent. Speech perseveration is exemplified by repeatedly returning to the same topic after it has lost its initial relevance. Catatonic combativeness usually occurs in an undirected manner, with no, or only a facile explanation afterwards. Autonomic abnormalities include changes in temperature, blood pressure, heart and respiratory rate, and diaphoresis.

\section{SUBTYPES OF CATATONIA}

Malignant catatonia and periodic catatonia are two major subtypes of catatonia. ${ }^{23}$ Malignant catatonia is characterised by sudden development of intense excitement, delirium, high fever, hypertension, catalepsy, mutism, rigidity, stereotypies and posturing. ${ }^{23}$ Because of accompanying marked autonomic instability and hyperthermia this form of catatonia is potentially fatal. $^{24}$ The neuroleptic malignant syndrome (NMS) is considered by some as a medication-induced variant of (malignant) catatonia. ${ }^{25}$ Numerous medical conditions leading to malignant catatonia have been reported. Although randomised clinical trials are lacking, electroconvulsive therapy (ECT) is effective in the treatment of malignant catatonia. ${ }^{26}$

Periodic catatonia has a rapid onset and consists of brief, recurrent hypokinetic or hyperkinetic abnormalities with episodes lasting 4-10 days which recur over a period of weeks to years. ${ }^{27}$ Patients are generally asymptomatic between episodes, but may exhibit inter-ictal facial grimacing, stereotypies and negativism, particularly late in the course of the illness. ${ }^{28}$ Periodic catatonia is rare and appears to segregate within families in an autosomal dominant pattern. There is evidence for linkage to long arm of chromosome $15 \mathrm{q} 15$ which was replicated in two independent genome-wide linkage scans based on over 12 multigenerational pedigrees. ${ }^{28}$ Overall, periodic catatonia is considered to have a better prognosis than the malignant form of catatonia.

\section{DIAGNOSTIC CHALLENGES}

The definition of catatonia both historically as well as in the DSM-V criteria is very broad. Although only 12 clinical features are included in the DSM-V diagnostic criteria, Kahlbaum in his original description listed 17 signs, and other authors have extended this list, some identifying 40 or more phenomena. ${ }^{15} 29$ The various phenomenological features are defined differently by different authors creating ambiguity and lack of clear definition. The DSM-V list of the various motor and speech abnormalities is too vague and it does not capture the true clinical picture of catatonia. Very opposing (eg, immobility vs excessive motor activity, mutism vs echolalia) or closely similar (eg, posturing vs catalepsy) motor and speech abnormalities are listed in parallel and are given equal diagnostic weight. The published diagnostic criteria and rating scales do not provide sufficient guidance as to how to reconcile between different combinations of clinical findings. For example, facial grimacing, phonic stereotypies, echopraxia and echolalia can be seen not only in patients with catatonia but also in Tourette syndrome, neuroacanthocytosis, autism and other neurological disorders. This overlap with various disorders indicates that catatonia is a symptom or a syndrome with different aetiologies rather than a single clinical entity.

Several studies have examined the discriminative value of various catatonia symptoms. One study found that 9 of the 12 items that are included in DSM-V possess very high discriminating value for catatonia, but noted that three items (agitation, stereotypies and mannerisms) had a weak correlation with catatonia. A subsequent study ${ }^{29}$ found that stereotypies and mannerisms also to have high discriminating value for catatonia.

The lack of single unifying phenotype or a set of highly sensitive and specific diagnostic criteria makes the diagnosis of catatonia challenging for the clinician, even experienced movement disorder specialist. ${ }^{30}$ The diagnosis may be especially difflt in the acute inpatient setting or in the ICU. ${ }^{14}$ Differentiating catatonia from delirium is especially important, as catatonia is treated with benzodiazepines whereas delirium may be exacerbated by benzodiazepine. The lack of motor and speech abnormalities in delirium helps to differentiate it from catatonia. On the other hand serotonin syndrome, central nervous system infection, autoimmune encephalopathy or some other medical and neurological conditions encountered in the acute hospital setting may overlap with signs of catatonia, and in some cases necessitate concomitant treatment for both catatonia and the underlying condition. In the absence of any clinical, physiological, imaging or other diagnostic markers that are reasonably sensitive and specific in defining catatonia, the diagnosis rests on the clinical history and observation of characteristic signs.

\section{PATHOPHYSIOLOGY}

The specific pathophysiological mechanisms underlying catatonia are not well understood. Neurochemical studies have focused on the inhibitory neurotransmitter $\gamma$-aminobutyric acid (GABA) A. The role of GABA in catatonia is supported by the observation of a dramatic response to treatment with benzodiazepines and zolpidem, both GABA A agonists, in patients with catatonia. $^{12}$ 31-33 The GABAergic hypothesis is also supported by the observation that ECT, which is used in drug resistant catatonia or as a fist-line therapy in malignant catatonia, also enhances GABA function. Furthermore, the single photon emission tomography (SPECT) with iodine-123-iomazenil showed significantly lower iomazenil binding, an index of benzodiazepine GABA-A receptor density, in the left sensorimotor cortex of patients with akinetic catatonia compared to psychiatric and healthy controls. ${ }^{34}$

There are case series and case reports showing the effectiveness of N-Methyl-D-aspartate (NMDA)-antagonists ${ }^{35}$ in catatonia, suggesting that glutamate hyperactivity might be related to catatonic symptoms. ${ }^{36}$ It has been postulated that NMDA 
hyperactivity causes dysregulation of GABA-A function and that NMDA antagonists can indirectly restore GABA-A function in the frontal lobes, though more slowly than GABA-A agonists. ${ }^{36}$

In addition, there is an increased familial transmission in first degree relatives, particularly for periodic catatonia (27\%) versus general catatonia $(5 \%)$ suggesting a genetic link. ${ }^{37}$ Several other pathophysiologic models of catatonia have been proposed notably motor circuitry dysfunction and a link to epilepsy, endocrine and immune dysfunction ${ }^{24}$ but there are insufficient data to substantiate these hypotheses and further studies are needed.

\section{AETIOLOGY}

Catatonia can occur in the setting of number of aetiologies (table 1). The disorder is increasingly recognised as a comorbid syndrome of autism, autism spectrum disorders and patients with intellectual disability. ${ }^{38-43}$ In adolescents with autism the prevalence of catatonia is between $12 \%$ and $17 \% .^{40}{ }^{44}$ It is important for clinicians to be aware of the possibility of catatonia when investigating reasons for the deterioration in skills and behaviour occurring in adolescents and adults with autistic spectrum disorders.

Catatonia is also recognised in the setting of various autoimmune disorders including anti-NMDA receptor (anti-NMDAR) encephalitis, ${ }^{45}$ that is typically found in young women with ovarian teratomas, but can be also encountered in men and in adults aged 45 years and above. ${ }^{46}$ The encephalitis is less severe in patients aged $\geq 45$ years than in young adults, but the outcome is poorer in older patients, partly because of delays in diagnosis and treatment. Anti-NMDAR encephalitis typically begins with a prodrome of a febrile, flu-like illness, which is followed by a spectrum of neuropsychiatric sequelae such as behavioural and cognition symptoms, memory deficit, psychosis, speech disorder, seizures, dysautonomia and hypoventilation. ${ }^{47}$ Movement disorders associated with anti-NMDAR encephalitis include chorea, athetosis, stereotypies (particularly involving the orofacial region), dystonia, ataxia, facial and limb myorhythmia, and opisthotonus. The exact prevalence of catatonia in anti-NMDAR encephalitis is unknown but many patients exhibit physical manifestations consistent with catatonia which may include mutism, facial and limb stereotypies, facial grimacing, staring episodes, waxy flexibility and posturing among others. $^{45} 48$ Treatment of this condition is mainly focused on tumour resection and immunotherapy. However, when associated with catatonia it can be underdiagnosed and inadequately treated. A treatment algorithm which includes management of catatonia was recently published. ${ }^{49}$ Other autoimmune encephalopathies such as systemic lupus erythematosus and antiphospholipid syndrome as well as infectious encephalitis can also present with catatonia ${ }^{50}$ (table 1).

\section{TREATMENT}

Before discussing various treatment strategies in catatonia it is important to note that many recommended treatments have not been subjected to rigorous, controlled trials. Furthermore, the currently available rating scales, such used to monitor response to treatment, as the BFCRS, lack the sensitivity necessary to measure minimal clinically meaningful improvements. ${ }^{18}$ One of the challenges in using rating scales is that catatonic symptoms fluctuate over time and may require longer periods of observation to obtain the full clinical picture. While the patient is been treated for catatonia it is also very important that an underlying aetiological cause is searched and treated without delay.
Table 1 Underlying causes of catatonia (other than schizophrenia and mood disorder)




Table 1 Continued

Deep brain stimulation surgery
Burns
Trauma
Other causes
Cyber bulling
Deprivation, abuse or trauma in pediatric population
Pregnancy or postpartum
Down syndrome
Wasp sting

*Most frequently reported causes of catatonia.

Anti-NMDAR, anti-N-Methyl-d-aspartate; CNS, central nervous system.

Benzodiazepines are widely considered the first-line treatment for catatonia, which can provide a rapid and dramatic improvement in symptoms 5152 (table 2).

There are no double-blind randomised controlled trials documenting the efficacy of benzodiazepine in catatonia. ${ }^{53}$ The evidence comes from a number of case series and case reports which document a response rate of $60-80 \% .^{2} 612$ Among the benzodiazepines, lorazepam is often selected as the drug of choice, which can be administered orally or parenterally. An open trial involving 13 acute catatonic patients, $2 \mathrm{mg}$ of intravenous lorazepam reduced catatonia scores on the BFCRS by $60 \%$ within 10 min. ${ }^{12}$ The typical starting daily dose is $3 \mathrm{mg} /$ day which can be titrated up as necessary. Dosages of $20-30 \mathrm{mg}$ /day in divided doses are occasionally necessary and the response can be quite dramatic. Within $3 \mathrm{~h}$ of receiving lorazepam 1-3 mg sublingually or intramuscularly, the vast majority of catatonic patients, who have been immobile, mute, withdrawn and refusing to eat or drink, enjoy complete release from their symptoms. Once the troublesome symptoms are controlled the effective dose of lorazepam that achieved a complete resolution of the catatonic signs should be maintained for several days until the underlying cause of catatonia is found and appropriately treated. ${ }^{54}$

Intravenous test dose of lorazepam (1-2 mg) can also be used as a diagnostic test for catatonia. ${ }^{65}$ The reduction or the full relief of catatonia symptoms within a few minutes is diagnostic. Absence of the response, however, does not rule out the diagnosis of catatonia as approximately $20 \%$ of participants do not respond to such a challenge. ${ }^{12}$ While benzodiazepines are safe medications when used in the short term, several issues should be kept in mind during treatment such as sedation and the risk of hypoventilation in patients with obesity, or those with obstructive sleep apnoea, falls in elderly patients or those with balance problems. ${ }^{54}$

Zolpidem (10 mg/day), a non-benzodiazepine GABA agonist of the imidazopyridine class that potentiates GABA by binding to GABA-A receptors at the same location as benzodiazepines was reported to improve catatonic symptoms. ${ }^{32}$ Zolpidem is increasingly recognised as another pharmacological treatment option for catatonia and is even suggested as an effective and prompt pharmacological test for catatonia. ${ }^{56}$

NMDA receptor antagonists have been shown to be effective in catatonia based on case series and multiple care reports. ${ }^{35} 36$ Amantadine and memantine which exert NMDA receptor antagonist effect are reported to be effective in catatonia. ${ }^{36}$ Amantadine doses from 100 up to $400 \mathrm{mg} /$ day have been used and memantine $10 \mathrm{mg} /$ day up to $20 \mathrm{mg} /$ day have been shown to be effective. ${ }^{36}$ Memantine, unlike amantadine, has no significant effects on dopamine neurotransmission. ${ }^{3657}$ Other medications, including topiramate, amobarbital, tetrabenazine, corticosteroids and rituximab have all been used as either primary or adjunctive treatments for catatonia with variable and poorly documented success (table 2).

Neuroleptics, particularly typical antipsychotics, are generally not recommended as treatment for acute catatonia, even for catatonic episodes due to schizophrenia. ${ }^{2}$ Indeed, there is some evidence that classic antipsychotics may precipitate malignant catatonia and NMS, underscoring again the importance of correctly diagnosing the disorder. ${ }^{26} 58$ This is an important issue in treating patients presenting with psychosis and catatonia. The literature on the use of atypical antipsychotics in catatonia consists of case reports and retrospective studies. ${ }^{58}$ One retrospective study found that clozapine stood out uniquely as an antipsychotic agent that was uniformly beneficial. There are several case reports showing benefit with olanzapine. Quetiapine has also been used in patients with acute catatonic schizophrenia with good outcome as well as risperidone. ${ }^{59}$

ECT has long been known to be particularly effective for catatonia, regardless of the aetiology. ${ }^{2} 60$ Although there is lack of data from randomised clinical trials supporting its efficacy and safety, ECT has been shown to be effective in cases of medication refractory catatonia. A retrospective study involving 27 patients (85\% were resistant to medical therapy), 59\% improved with ECT, especially younger patients with autonomic dysregulation. ${ }^{61}$ Authors concluded that daily administration of ECT may be more effective, whereas longer duration of seizure activity at the final ECT session was related to better response to ECT. ${ }^{61}$ In order to provide more lasting improvement, daily treatments for 2-5 days may be required. ${ }^{62}$ There are other studies showing effectiveness of ECT to range from $85 \%$ to $93 \%$ in catatonia patients. ${ }^{63}$ In a retrospective study involving 63 patients with catatonia, the fast responders were the ones with a shorter duration of illness illustrating the fact that early detection of illness plays a crucial role in treatment response. ${ }^{63}$ In the same study, participants with waxy flexibility and gegenhalten showed a faster response rate, while participants with echophenomena showed a slower response. ${ }^{63}$ Although there are no absolute contraindications to ECT, this treatment intervention should not be considered first-line therapy except for life-threatening malignant catatonia. ${ }^{2}{ }^{62}$ Mortality in malignant catatonia may increase if ECT is not begun within 5 days of symptom onset. ${ }^{15}$ Some cases of catatonia may require maintenance ECT to prevent recurrent episodes. Although controlled trials are lacking the effectiveness of benzodiazepines and ECT in anti-NMDAR encephalitis and other paraneoplastic encephalitis has been well documented. ${ }^{45} 39$

Fast repetitive transcranial magnetic stimulation of the left dorsolateral prefrontal cortex was also reported to be effective in two case reports $(10 \mathrm{~Hz})^{64}$ Although the long-term outcome of catatonia has not been rigorously studied, catatonia appears to have a generally favourable prognosis. ${ }^{2}$

\section{SUMMARY}

Catatonia is a neuropsychiatric disorder that encompasses a wide range of movement disorders. As there is no catatonia-specific biomarker, recognition of the characteristic clinical features is critical to the diagnosis. Catatonia is no longer considered a subtype of schizophrenia and can be seen in the setting of other psychiatric disorders, general medical, neurological and surgical conditions, as well as drugs and toxic substances. The underlying pathophysiological mechanisms are still not clear and a 'GABA hypothesis' has been proposed. Most patients respond well to benzodiazepines or ECT and prompt treatment in the early phases of catatonia is important for the best outcome. The exact prevalence of idiopathic catatonia is unknown. However it is important that an underlying cause of the catatonia is identified 
Movement disorders

Table 2 Studies on treatment of catatonia

\begin{tabular}{|c|c|c|}
\hline Medication & Type of study & Conclusion \\
\hline $\begin{array}{l}\text { Lorazepam } \\
\text { Ungvari et al }\end{array}$ & $\begin{array}{l}\text { A randomised, double-blind, } \\
\text { placebo-controlled cross-over study of } 18 \\
\text { patients }\end{array}$ & Not effective in chronic schizophrenia with catatonia \\
\hline $\begin{array}{l}\text { Lorazepam/ECT } \\
\text { Bush et al }{ }^{12}\end{array}$ & Prospective study of 28 patients & $\begin{array}{l}\text { Sixteen of the } 21 \text { who completed treatment showed benefit. Four patients that } \\
\text { failed lorazepam responded to ECT }\end{array}$ \\
\hline $\begin{array}{l}\text { Lorazepam } \\
\text { Tibrewal et al }{ }^{55}\end{array}$ & Retrospective study of 107 & $\begin{array}{l}\text { Thirty two of } 99(32.3 \%) \text { showed response (with complete resolution of } \\
\text { catatonic symptoms). Improvement in catatonic symptoms was seen in } 68 \text { of } 99 \\
(68.7 \%) \text { patients }\end{array}$ \\
\hline $\begin{array}{l}\text { Lorazepam-diazepam } \\
\text { Lin and Huang }\end{array}$ & Retrospective study of 21 patients & $\begin{array}{l}\text { Among } 21 \text { patients } 13 \text { (61.9\%) patients responded within } 2 \mathrm{~h}, 18 \text { (85.7\%) } \\
\text { responded within } 1 \text { day, and all became catatonia-free within a week }\end{array}$ \\
\hline $\begin{array}{l}\text { Lorazepam-diazepam } \\
\text { Huang et a }{ }^{65}\end{array}$ & Retrospective study of 12 patients & $\begin{array}{l}\text { Eight patients complete remission (one dose of } 2 \mathrm{mg} \text { lorazepam intramuscularly } \\
\text { (IM)). Two patients needed two doses of } 2 \mathrm{mg} \text { lorazepam IM. Two patients } \\
\text { failed lorazepam but responded to one dose of } 10 \mathrm{mg} \text { diazepam intravenous. All } \\
\text { catatonic features remitted in } 24 \mathrm{~h} \text { with } 100 \% \text { response rate }\end{array}$ \\
\hline $\begin{array}{l}\text { Lorazepam and risperidone } \\
\text { Grenier et } a^{66} ; \text { Prakash et } a^{67}\end{array}$ & Case reports & Effective in two case reports \\
\hline $\begin{array}{l}\text { Zolpidem } \\
\text { Cottencin et } a l^{33}\end{array}$ & Case series 12 patients & $\begin{array}{l}\text { Zolpidem was used as a diagnostic test in } 6 \text { out of the } 12 \text { patients. Response } \\
\text { was seen in } 4 \text { and no response in } 2 \text { patients }\end{array}$ \\
\hline $\begin{array}{l}\text { Zolpidem } \\
\text { Peglow et }\left.a\right|^{32}\end{array}$ & Case report & Effective in case report \\
\hline $\begin{array}{l}\text { Amantadine } \\
\text { de Lucena et }\left.a\right|^{35}\end{array}$ & Case series five patients & Effective in case series \\
\hline $\begin{array}{l}\text { Amantadine } \\
\text { Hervey et } a l^{68} ; \text { Ene-Stroescu et } a^{69}\end{array}$ & Case reports & Effective in case reports \\
\hline Amantadine/memantine & Case reports 25 patients & Effective in case reports \\
\hline $\begin{array}{l}\text { Memantine } \\
\text { Obregon et }\left.a\right|^{57}\end{array}$ & Case report & Effective in case report \\
\hline $\begin{array}{l}\text { Topiramate } \\
\text { McDaniel et al }{ }^{70}\end{array}$ & Case series 4 patients & Effective in case series \\
\hline $\begin{array}{l}\text { Olanzapine or clozapine } \\
\text { Nicolato et } a^{71} ; \text { Chang et al a }{ }^{72} ; \text { Spiegel }^{73} \text {; } \\
\text { Chattopadhyay et al al } ; \text { Ueda et al } l^{75}\end{array}$ & Case reports and case series & Effective in case reports and case series \\
\hline $\begin{array}{l}\text { Olanzapine and amantadine } \\
\text { Babington et } a l^{76}\end{array}$ & Case report & Effective in case report \\
\hline $\begin{array}{l}\text { Quetiapine } \\
\text { Yoshimura et } a l^{77}\end{array}$ & Case series 39 patients & Effective in case series \\
\hline $\begin{array}{l}\text { Risperidone } \\
\text { Kopala et } a l^{78} ; \text { Hesslinger et } a l^{59}\end{array}$ & Case reports & Effective in case reports \\
\hline $\begin{array}{l}\text { ECT } \\
\text { Raveendranathan et } a l^{63}\end{array}$ & Retrospective study 63 patients & Response to ECT was noticed in 56 out of 63 patients $(88.89 \%)$. \\
\hline $\begin{array}{l}\text { ECT } \\
\text { van Waarde et } a^{61}\end{array}$ & Retrospective study 27 & Improvement was seen in $16(59 \%)$ patients \\
\hline $\begin{array}{l}\text { ECT } \\
\text { Rohland et al }\end{array}$ & Retrospective study with 22 patients & Improvement was seen in 26 out of 28 cases $(93 \%)$ \\
\hline $\begin{array}{l}\text { ECT and olanzapine } \\
\text { Tan et } a l^{80}\end{array}$ & Case report & Effective in case report \\
\hline
\end{tabular}

$\mathrm{ECT}$, electroconvulsive therapy.

and treated to ensure early and complete resolution of symptoms. Further studies are clearly needed to help better characterise the clinical features and to improve our understanding of the pathophysiology of this unique condition with the aim to develop pathogenesis-targeted preventive therapies and better symptomatic treatments.

Acknowledgements The authors would like to thank Dr Amber Stocco for providing online supplementary videos 2 and 3 that accompany this manuscript.

Contributors SW involved in the manuscript preparation, writing of the first draft. $\mathrm{JJ}$ involved in the manuscript review and critique.

Competing interests JJ has no competing interests but during the past 2 years has received: Current Research and Center of Excellence Grants: Adamas Pharmaecuticals, Inc (amantadine); Allergan, Inc (botulinum toxin); Auspex Pharmaceuticals, Inc (SD809); CHDI Foundation; GE Healthcare; Great Lakes
NeuroTechnologies; Huntington's Disease Society of America; Huntington Study Group; Ipsen Limited; Kyowa Haako Kirin Pharma, Inc (istradefylline); Lundbeck Inc (tetrabenazine); Medtronic; Merz Pharmaceuticals; Michael J Fox Foundation for Parkinson Research; National Institutes of Health; National Parkinson Foundation; Omeros Corporation (OMS824); Parkinson Study Group; Pharma Two B; Prothena Biosciences Inc (PRX002); Psyadon Pharmaceuticals (ecopipam), Inc; St. Jude Medical; Teva Pharmaceutical Industries Ltd; UCB Inc; University of Rochester; Current consultant or an advisory committee member: Allergan, Inc; Auspex Pharmaceuticals, Inc; Ipsen Biopharmaceuticals, Inc; Lundbeck Inc; Teva Pharmaceutical Industries Ltd. Royalties: Cambridge; Elsevier; Future Science Group; Hodder Arnold; Lippincott Williams and Wilkins; Wiley-Blackwell. During the past 2 years $\mathrm{JJ}$ has served on the following editorial boards and foundation advisory boards: Editorial boards: Medlink: Neurology; Expert Review of Neurotherapeutics; Neurology in Clinical Practice; The Botulinum Journal; PeerJ; Therapeutic Advances in Neurological Disorders; Neurotherapeutics; Tremor and Other Hyperkinetic Movements; Journal of Parkinson's Disease; UpToDate. Speakers Bureau: none; Stock Ownership: none. SW has no competing interests.

Provenance and peer review Not commissioned; externally peer reviewed. 


\section{REFERENCES}

1 Kahlbaum KL. Catatonia. Translated by Levi Y, Pridon T. Johns Hopkins University Press, 1973.

2 Francis A. Catatonia: diagnosis, classification, and treatment. Curr Psychiatry Rep 2010;12:180-5.

3 Pfuhlmann B, Stober G. The different conceptions of catatonia: historical overview and critical discussion. Eur Arch Psychiatry Clin Neurosci 2001;251(Suppl 1):14-7.

4 van der Heijden FM, Tuinier S, Arts NJ, et al. Catatonia: disappeared or under-diagnosed? Psychopathology 2005;38:3-8.

5 Fink M, Shorter E, Taylor MA. Catatonia is not schizophrenia: Kraepelin's error and the need to recognize catatonia as an independent syndrome in medical nomenclature. Schizophr Bull 2010;36:314-20.

6 Daniels J. Catatonia: clinical aspects and neurobiological correlates. J Neuropsychiatry Clin Neurosci 2009:21:371-80.

7 Francis $A$, Fink $M$, Appiani $F$, et al. Catatonia in diagnostic and statistical manual of mental disorders, fifth edition. J ECT 2010;26:246-7.

8 Rosebush PI, Hildebrand AM, Furlong BG, et al. Catatonic syndrome in a general psychiatric inpatient population: frequency, clinical presentation, and response to lorazepam. J Clin Psychiatry 1990;51:357-62.

9 Chalasani P, Healy D, Morriss R. Presentation and frequency of catatonia in new admissions to two acute psychiatric admission units in India and Wales. Psychol Med 2005;35:1667-75.

10 Taylor MA, Fink M. Catatonia in psychiatric classification: a home of its own. Am J Psychiatry 2003;160:1233-41.

11 Smith JH, Smith VD, Philbrick KL, et al. Catatonic disorder due to a general medical or psychiatric condition. J Neuropsychiatry Clin Neurosci 2012;24: 198-207.

12 Bush G, Fink M, Petrides G, et al. Catatonia. II. Treatment with lorazepam and electroconvulsive therapy. Acta Psychiatr Scand 1996;93:137-43.

13 Jaimes-Albornoz W, Serra-Mestres J. Catatonia in the emergency department. Emerg Med J 2012;29:863-7.

14 Saddawi-Konefka D, Berg SM, Nejad SH, et al. Catatonia in the ICU: an important and underdiagnosed cause of altered mental status. A case series and review of the literature* . Crit Care Med 2014;42:e234-41.

15 Fink MT, Taylor MA. Catatonia. A clinician's guide to diagnosis and treatment. Cambridge, UK: Cambridge University Press, 2003.

16 Tuerlings JH, van Waarde JA, Verwey B. A retrospective study of 34 catatonic patients: analysis of clinical care and treatment. Gen Hosp Psychiatry 2010;32:631-5.

17 American Psychiatric Association. Diagnostic and statistical manual of mental disorders: DSM-V. Washington DC: American Psychiatric Association, 2013.

18 Sienaert P, Rooseleer J, De Fruyt J. Measuring catatonia: a systematic review of rating scales. J Affect Disord 2011;135:1-9.

19 Bush G, Fink M, Petrides G, et al. Catatonia. I. Rating scale and standardized examination. Acta Psychiatr Scand 1996;93:129-36.

20 Bush G, Petrides G, Francis A. Catatonia and other motor syndromes in a chronically hospitalized psychiatric population. Schizophr Res 1997;27:83-92.

21 Azzam PN, Gopalan P. Prototypes of catatonia: diagnostic and therapeutic challenges in the general hospital. Psychosomatics 2013:54:88-93.

22 Morris JC, Jankovic J. Neurological clinical examination. London, UK: Hodde Arnold, 2012:1-128.

23 Fink M, Taylor MA. The many varieties of catatonia. Eur Arch Psychiatry Clin Neurosci 2001:251(Suppl 1):18-13.

24 Dhossche DM, Stoppelbein L, Rout UK. Etiopathogenesis of catatonia: generalizations and working hypotheses. J ECT 2010;26:253-8.

25 Fink M, Taylor MA. Neuroleptic malignant syndrome is malignant catatonia, warranting treatments efficacious for catatonia. Prog Neuropsychopharmacol Biol Psychiatry 2006;30:1182-3; author reply 1184-1185.

26 Fink M. Rediscovering catatonia: the biography of a treatable syndrome. Acta Psychiatr Scand Supp/ 2013;(441):1-47.

27 Hervey WM, Stewart JT, Catalano G. Diagnosis and management of periodic catatonia. J Psychiatry Neurosci 2013:38:E7-8.

28 Stober G, Saar K, Ruschendorf F, et al. Splitting schizophrenia: periodic catatonia-susceptibility locus on chromosome 15q15. Am J Hum Genet 2000;67: 1201-7.

29 Peralta V, Campos MS, de Jalon EG, et al. DSM-IV catatonia signs and criteria in first-episode, drug-naive, psychotic patients: psychometric validity and response to antipsychotic medication. Schizophr Res 2010;118:168-75.

30 Ungvari GS, Caroff SN, Gerevich J. The catatonia conundrum: evidence of psychomotor phenomena as a symptom dimension in psychotic disorders. Schizophr Bull 2010;36:231-8.

31 Ungvari GS, Chiu HF, Chow LY, et al. Lorazepam for chronic catatonia: a randomized, double-blind, placebo-controlled cross-over study. Psychopharmacology (Berl) 1999;142:393-8.

32 Peglow S, Prem V, McDaniel W. Treatment of catatonia with zolpidem. J Neuropsychiatry Clin Neurosci 2013;25:E13.

33 Cottencin O, Warembourg F, de Chouly de Lenclave MB, et al. Catatonia and consultation-liaison psychiatry study of 12 cases. Prog Neuropsychopharmacol Biol Psychiatry 2007;31:1170-6.
34 Northoff G, Steinke R, Czcervenka C, et al. Decreased density of GABA-A receptors in the left sensorimotor cortex in akinetic catatonia: investigation of in vivo benzodiazepine receptor binding. J Neurol Neurosurg Psychiatry 1999;67:445-50.

35 de Lucena DF, Pinto JP, Hallak JE, et al. Short-term treatment of catatonia with amantadine in schizophrenia and schizoaffective disorder. J Clin Psychopharmacol 2012;32:569-72.

36 Carroll BT, Goforth HW, Thomas C, et al. Review of adjunctive glutamate antagonis therapy in the treatment of catatonic syndromes. J Neuropsychiatry Clin Neurosci 2007; 19:406-12

37 Stober G, Seelow D, Ruschendorf F, et al. Periodic catatonia: confirmation of linkage to chromosome 15 and further evidence for genetic heterogeneity. Hum Genet 2002;111:323-30.

38 Dhossche DM, Wachtel LE. Catatonia is hidden in plain sight among different pediatric disorders: a review article. Pediatr Neurol 2010;43:307-15.

39 Fink M, Taylor MA, Ghaziuddin N. Catatonia in autistic spectrum disorders: a medical treatment algorithm. Int Rev Neurobiol 2006;72:233-44.

40 Wing L, Shah A. Catatonia in autistic spectrum disorders. Br J Psychiatry 2000;176:357-62

41 Ohta M, Kano Y, Nagai Y. Catatonia in individuals with autism spectrum disorders in adolescence and early adulthood: a long-term prospective study. Int Rev Neurobiol 2006;72:41-54.

42 Dhossche DM, Reti IM, Wachtel LE. Catatonia and autism: a historical review, with implications for electroconvulsive therapy. J ECT 2009;25:19-22.

43 Dejong $\mathrm{H}$, Bunton $\mathrm{P}$, Hare DJ. A systematic review of Interventions used to treat catatonic symptoms in people with autistic spectrum disorders. J Autism Dev Disord 2014:44:2127-36.

44 Billstedt E, Gillberg IC, Gillberg C. Autism after adolescence: population-based 13to 22-year follow-up study of 120 individuals with autism diagnosed in childhood. J Autism Dev Disord 2005;35:351-60.

45 Dhossche $D$, Fink $M$, Shorter $E$, et al. Anti-NMDA receptor encephalitis versus pediatric catatonia. Am J Psychiatry 2011;168:749-50; author reply 750

46 Titulaer MJ, McCracken L, Gabilondo I, et al. Late-onset anti-NMDA receptor encephalitis. Neurology 2013;81:1058-63.

47 Mann AP, Grebenciucova E, Lukas RV. Anti-N-methyl-D-aspartate-receptor encephalitis: diagnosis, optimal management, and challenges. Ther Clin Risk Manag 2014; 10:517-25

48 Baizabal-Carvallo JF, Stocco A, Muscal $E$, et al. The spectrum of movement disorders in children with anti-NMDA receptor encephalitis. Mov Disord 2013;28:543-7.

49 Kruse JL, Jeffrey JK, Davis MC, et al. Anti-N-methyl-d-aspartate receptor encephalitis: a targeted review of clinical presentation, diagnosis, and approaches to psychopharmacologic management. Ann Clin Psychiatry 2014;26:E1-9.

50 Baizabal-Carvallo JF, Jankovic J. Movement disorders in autoimmune diseases. Mov Disord 2012;27:935-46.

51 Ungvari GS, Leung CM, Wong MK, et al. Benzodiazepines in the treatment of catatonic syndrome. Acta Psychiatr Scand 1994;89:285-8.

52 Lin CC, Huang TL. Lorazepam-diazepam protocol for catatonia in schizophrenia: a 21-case analysis. Compr Psychiatry 2013;54:1210-14

53 Gibson RC, Walcott G. Benzodiazepines for catatonia in people with schizophrenia and other serious mental illnesses. Cochrane Database Syst Rev 2008;(4): CD006570.

54 Rosebush PI, Mazurek MF. Catatonia and its treatment. Schizophr Bull 2010;36:239-42.

55 Tibrewal P, Narayanaswamy J, Zutshi A, et al. Response rate of lorazepam in catatonia: a developing country's perspective. Prog Neuropsychopharmacol Biol Psychiatry 2010;34:1520-2.

56 Thomas P, Rascle C, Mastain B, et al. Test for catatonia with zolpidem. Lancet 1997;349:702.

57 Obregon DF, Velasco RM, Wuerz TP, et al. Memantine and catatonia: a case report and literature review. J Psychiatr Pract 2011;17:292-9.

58 Van Den Eede F, Van Hecke J, Van Dalfsen A, et al. The use of atypical antipsychotics in the treatment of catatonia. Eur Psychiatry 2005;20:422-9.

59 Hesslinger B, Walden J, Normann C. Acute and long-term treatment of catatonia with risperidone. Pharmacopsychiatry 2001;34:25-6

60 Zisselman MH, Jaffe RL. ECT in the treatment of a patient with catatonia: consent and complications. Am J Psychiatry 2010;167:127-32.

61 van Waarde JA, Tuerlings JH, Verwey B, et al. Electroconvulsive therapy for catatonia: treatment characteristics and outcomes in 27 patients. J ECT 2010;26:248-52.

62 Fink M, Taylor MA. The catatonia syndrome: forgotten but not gone. Arch Gen Psychiatry 2009;66:1173-7

63 Raveendranathan D, Narayanaswamy JC, Reddi SV. Response rate of catatonia to electroconvulsive therapy and its clinical correlates. Eur Arch Psychiatry Clin Neurosci 2012;262:425-30

64 Saba G, Rocamora JF, Kalalou K, et al. Catatonia and transcranial magnetic stimulation. Am J Psychiatry 2002;159:1794

65 Huang YC, Lin CC, Hung YY, et al. Rapid relief of catatonia in mood disorder by lorazepam and diazepam. Biomed J 2013;36:35-9.

66 Grenier $\mathrm{E}$, Ryan $\mathrm{M}$, Ko $\mathrm{E}$, et al. Risperidone and lorazepam concomitant use in clonazepam refractory catatonia: a case report. J Nerv Ment Dis 2011;199:987-8. 
67 Prakash O, Bagepally BS. Catatonia and mania in patient with AIDS: treatment with lorazepam and risperidone. Gen Hosp Psychiatry 2012;34:321 e325-6.

68 Hervey WM, Stewart JT, Catalano G. Treatment of catatonia with amantadine. Clin Neuropharmacol 2012;35:86-7.

69 Ene-Stroescu V, Nguyen T, Waiblinger BE. Successful treatment of catatonia in a young man with schizophrenia and progressive diffuse cerebral atrophy. J Neuropsychiatry Clin Neurosci 2014;26:E21-2.

70 McDaniel WW, Spiegel DR, Sahota AK. Topiramate effect in catatonia: a case series. J Neuropsychiatry Clin Neurosci 2006;18:234-8.

71 Nicolato R, Romano-Silva MA, Correa $\mathrm{H}$, et al. Stuporous catatonia in an elderly bipolar patient: response to olanzapine. Aust N Z J Psychiatry 2006;40:498.

72 Chang $\mathrm{CH}$, Hsiao YL, Hsu CY, et al. Treatment of catatonia with olanzapine: a case report. Prog Neuropsychopharmacol Biol Psychiatry 2009;33:1559-60.

73 Spiegel DR, Varnell C, Jr. A case of catatonia due to posterior reversible encephalopathy syndrome treated successfully with antihypertensives and adjunctive olanzapine. Gen Hosp Psychiatry 2011;33:302 e303-305.
74 Chattopadhyay S, Saha I, Dan A, et al. Clozapine responsive catatonia: A series of five cases. Ind Psychiatry J 2012;21:66-8.

75 Ueda S, Takeuchi J, Okubo Y. Successful use of olanzapine for catatonia following delirium. Psychiatry Clin Neurosci 2012;66:465.

76 Babington PW, Spiegel DR. Treatment of catatonia with olanzapine and amantadine. Psychosomatics 2007;48:534-6.

77 Yoshimura B, Hirota T, Takaki M, et al. Is quetiapine suitable for treatment of acute schizophrenia with catatonic stupor? A case series of 39 patients. Neuropsychiatr Dis Treat 2013;9:1565-71.

78 Kopala LC, Caudle C. Acute and longer-term effects of risperidone in a case of firstepisode catatonic schizophrenia. J Psychopharmacol 1998;12:314-7.

79 Rohland BM, Carroll BT, Jacoby RG. ECT in the treatment of the catatonic syndrome. J Affect Disord 1993;29:255-61.

80 Tan QR, Wang W, Wang HH, et al. Treatment of catatonic stupor with combination of modified electroconvulsive treatment and olanzapine: a case report. Clin Neuropharmacol 2006;29:154-6. 